\title{
Deskripsi Sikap Kedisiplinan Peserta Didik pada Mata Pelajaran IPA di
} SMPN 19 Kota Jambi

\author{
Afrina Witri $^{1}$, Rini Siski Fitriani ${ }^{2}$ \\ ${ }^{1}$ SMAN 10 Tebo, Jambi, Indonesia \\ ${ }^{2}$ Pendidikan Fisika, Universitas Jambi, Jambi, Indonesia
}

Article Info

Article history:

Received Jun 29, 2020

Revised Agu 4, 2020

Accepted Sep 7, 2020

\section{Keywords:}

IPA

Kedisiplinan

Sikap

\begin{abstract}
ABSTRAK
Tujuan Penelitian: Tujuan penelitian ini adalah untuk mengetahui sikap kedisiplinan siswa dalam mata pelajaran IPA di SMPN 19 Kota Jambi.

Metodologi: Penelitian ini adalah jenis penelitian kuantitatf dengan analisi data deskriptif. Data yang didapatkan berupa angka/numerik yang diolah dengan program SPSS 20. Subjek penelitian ini adalah 54 peserta didik SMPN 19 Kota Jambi.

Temuan utama: Hasil dari penelitian ini adalah dari data yang telah diolah menggunakan program SPSS didapatkan bahwa tingkat kedisiplinan peserta didik di SMPN 19 Kota Jambi berada pada kategori baik.

Keterbaruan penelitian: Adapun keterbaharuan dari penelitian ini adalah didapatkan hasil deskripsi sikap kedisiplinan peserta didik yang nantinya guru dapat mengukur sejauh mana peserta didik dispilin pada mata pelajaran IPA.
\end{abstract}

This is an open access article under the $\mathrm{CC} B Y-N C$ license

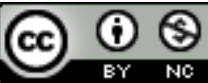

\section{Corresponding Author:}

Rini Siski Fitriani,

Program Studi Pendidikan Fisika,

Universitas Jambi,

Email: rinisiski@gmail.com

\section{PENDAHULUAN}

Pendidikan merupakan suatu proses pembelajaran untuk membentuk dan meningkatkan keterampilan serta pengetahuan seseorang agar menjadi manusia yang layak yang mampu menempatkan diri di lingkungan masyarakat [1]. Pendidikan memiliki peranan yang sangat penting bagi manusia untuk menghadapi kemanjuan zaman [2]. Kemajuan suatu bangsa salah satunya ditentukan dari aspek pendidikan [3]. Oleh karena itu upaya yang dilakukan untuk mencetak sumber daya manusia (SDM) yang berkualitas adalah dengan adanya pendidikan [4]. Sejalan dengan pendapat [5], bahwa pendidikan akan meningkatkan kualitas dan kuantitas seseorang. Pendidikan berfungsi untuk pengembangan karakter siswa [6]. Hasil dari pendidikan itu sendiri adalah membentuk peserta didik yang berkarakter dan memiliki sikap yang baik. Salah satu sikap yang harus dimiliki peserta didik adalah disiplin.

Disiplin yang dalam bahasa inggris "Discipline" adalah kepatuhan yang berkaitan dengan suatu peraturan atau tata tertib. Disiplin merupakan gambaran yang menyatakan hasil kegiatan atau perubahan yang telah dicapai oleh seseorang melalui keuletannya dalam bekerja, dari segi kualitas maupun kuantitas dilihat dari pengukuran dan penglihatan serta penelitian atau hasil usaha yang telah dilakukan [7]. Menurut [8], disiplin merupakan kesadaran untuk melakukan sesuatu hal dengan tertib dan teratur sesuai dengan peraturan-peraturan yang berlaku dengan penuh tanggung jawab tanpa paksaan dari siapa pun. Disiplin ada yang didasari kehendak dan dorongan dari dalam dirinya, dan ada juga tumbuh dan berkembang dari orang 
lain ataupun lingkungannya. Namun yang menjadi persoalan bagi kita adalah bagaimana mendisiplinkan anak didik untuk belajar yang sifatnya positif dan berhasil, dan dapat memberikan manfaat yang baik untuk dirinya sendiri, keluarga, lingkungan, dan bangsa serta negaranya. Belajar adalah suatu kebutuhan tanpa belajar maka kualitas seseorang akan menurun. Karena dengan belajar seseorang akan sadar untuk menjalani kehidupannya yang lebih baik lagi. Disiplin dalam belajar harus dilatih sejak kecil, karena dengan disiplin bisa mengatur belajar yang tepat dan belajar yang efisien. Kedisiplinan dalam belajar adalah kesadaran dari dalam diri yang bisa mengendalikan dan mengontrol dirinya sendiri untuk belajar dengan sungguh-sungguh [9]. Disiplin belajar siswa dimulai dari kebiasaan yang dilakukan yaitu, siswa mampu mempergunakan waktu yang baik, memiliki rasa tanggung jawab terhadap tugas yang diberikan dan menyusun jadwal pelajaran. Dalam pendidikan karakter kedisiplinan sangat penting bagi siswa karena menurut [10] presepsi masyarakat saat ini adalah menurunnya kualitas sikap dan moral generasi muda. Disiplin juga memiliki faktor-faktor penunjang yang bisa membentuk peserta didik ke arah yang lebih baik antara lain, faktor ekstrinsik, meliputi faktor nonsosial dan faktor sosial. Faktor non-sosial meliputi keadaan udara, suhu udara, waktu, tempat, dan alat-alat yang dipakai untuk perkuliahan. Sedangkan faktor sosial meliputi lingkungan keluarga, lingkungan masyarakat, dan lingkungan kelompok. Dan faktor intrinsik, meliputi fakor psikologi dan faktor fisiologi. Faktor psikologi, seperti minat, bakat, motivasi, konsentrasi, dan kemampuan kognitif. Sedangkan faktor fisiologis seperti pendengaran, penglihatan, kesegaran jasmani, keletihan, kekurangan gizi, kurang tidur, dan sakit yang diderita.

Kedisiplinan dalam belajar IPA juga sangat penting. Mata pelajaran IPA (Pelajaran Ilmu Pengetahuan Alam) pada hakekatnya adalah produk, proses, sikap dan teknologi [11]. Kurniawan (2019) menjelaskan bahwa "Essentially science lessons are product, processes, attitudes and technology" [12]. Pada dasarnya pelajaran sains/Fisika adalah produk, proses, sikap, dan teknologi. Pembelajaran IPA sebaiknya dilasanakan secara inkuiri ilmiah. Oleh karena itu sikap disiplin sangat penting dalam pembelajaran IPA. Mata pelajaran IPA di SMP terdiri dari dasar-dasar pelajaran Fisika, Kimia, dan Biologi dimana di setiap pelajaran itu ada eksperimen atau percobaan dengan langkah-langkah ilmiah. Diantara sikap ilmiah sikap disiplin juga sangat diperlukan sesaui dengan pengertian disiplin yaitu patuh terhadap tata tertib. Dalam melakukan eksperimen diperlukan sikap yang patuh dan menaaati peraturan. Kedisiplinan belajar merupakan faktor internal siswa karena timbul dari kesadaran diri sendiri. Sikap disiplin perlu ditanamkan pada setiap peserta didik. Cara-cara untuk menumbuhkan disiplin siswa dalam belajar antara lain, keteraturan dalam belajar karena dalam belajar yang teratu siswa akan menemukan sendiri gaya belajarnya , konsentrasi, tertib dalam belajar artinya bisa mengatur waktu kesehariannya utuk belajar.

Tujuan dari penelitian ini adalah peneliti ingin mengidentifikasi dan meilihat bagaimana sikap kedisiplinan pada pembelajaran IPA di SMPN 19 Kota Jambi.

\section{METODE PENELITIAN}

Penelitian ini adalah jenis penelitian kuantitatif. Menurut [13], penelitian kuantitatif merupakan penelitian yang menggunakan analisis data yang berbentuk numerik/angka. Pada penelitian kuantitatif alat pengumpul data/instrumen penelitian yang digunakan oleh peneliti dikembangkan dari jabaran penelitian yang dikembangkan dari teori-teori yang akan diuji dari kegiatan penelitian yang dikerjakan. Untuk itu sebelum instrumen penelitian yang dikembangkan digunakan untuk mengumpulkan data pada objek atau responden yang sesungguhnya, hendaknya instrumen tersebut diuji validitas dan reliabilitasnya.

Instrumen yang digunakan berupa angket Kedisiplinan Siswa yang diadaptasi dari penelitian [7-14] dengan jumlah pernyataan sebanyak 34 pernyataan. Subjek dari penelitian ini adalah peserta didik SMPN 19 Kota Jambi kelas VII E dan VII F yang berjumlah 54 peserta didik. Pengumpulan data dilakukan melalui pemberian instrumen, yaitu angket, angket (questionnaire) merupakan suatu daftar pertanyaan atau pernyataan tentang topik tertentu yang diberikan kepada subjek, baik secara individual atau kelompok, untuk mendapatkan informasi tertentu, seperti preferensi, keyakinan, minat dan perilaku [15]. Data dianalisis menggunakan software SPSS untuk mencari data statistik untuk mengidentifikasi sikap kedisipinan peserta didik pada mata pelajarn IPA.

\section{HASIL DAN PEMBAHASAN}

Keterhabaruan dari penelitian ini adalah mengetahui sikap kedisiplinan peserta didik pada mata pelajaran IPA di SMPN 19 Kota Jambi. Tujuan melakukan evaluasi terhadap sikap kedisiplinan peserta didik agar guru dapat mengukur sejauh mana tingkat kedisiplinan peserta didik pada mata pelajaran IPA. Hal ini akan mempengaruhi hasil belajar peserta didik. Adapaun data dari hasil penelitian yang telah dilakukan adalah sebagai berikut: 
Tabel 1. Deskriptif sikap kedispilinan peserta didik SMPN 19 Kota Jambi

\begin{tabular}{|c|c|c|c|c|c|c|c|}
\hline \multicolumn{4}{|c|}{ Klasifikasi } & \multirow[b]{2}{*}{ Mean } & \multirow[b]{2}{*}{ Min } & \multirow[b]{2}{*}{ Max } & \multirow[b]{2}{*}{$\%$} \\
\hline & Rentang & Respon & Jumlah & & & & \\
\hline & $34,0-59,5$ & Tidak Baik & 0 & & & & 0 \\
\hline & $59,6-85,0$ & Cukup & 2 & 121,66 & 76 & 167 & 1,9 \\
\hline \multirow{3}{*}{$\mathrm{U}$} & $86,0-110,5$ & Baik & 40 & & & & 72,2 \\
\hline & $110,6-136,0$ & Sangat Baik & 12 & & & & 18,5 \\
\hline & & & 54 & & & & 100 \\
\hline
\end{tabular}

Dari hasil penelitian yang telah dilakukan didapatkan data pada tabel diatas untuk sikap kedisiplinan siswa di SMPN 19 Kota Jambi. Pada kategori sangat baik yaitu 18,5 \% atau 12 peserta didik. Kategori baik $72,2 \%$ atau 40 peserta didik. Kategori cukup $1.9 \%$ atau 2 peserta didik, dan untuk kategori tidak baik presentase nya $0 \%$ atau tidak ada. Sikap disiplin terhadap pembelajaran IPA di SMPN 19 Kota Jambi sudah baik terbukti dari hasil penelitian sebanyak 40 peserta didik dari jumlah total 54 peserta didik memiliki sikap disiplin yang baik artinya saat pembelajaran IPA berlangsung para peserta didik disiplin.

Sains/IPA merupakan cabang ilmu tentang studi ilmiah tentang energi dan materi dan interaksinya satu sama lain [16]. Sains memiliki keunikan dan karakteristik tersendiri [17]. Keunikan sains yaitu pada konsep-konsepnya yang bersifat abstrak dan mengharuskan peserta didik berpikir tingaat tinggi [18]. Sejalan yang diungkapkan [19], bahwa konsep-konsep pada sains memerlukan pemahaman tingkat tinggi. Namun pada kenyataanya pembelajaran sains hanya ditekankan pada mengingat rumus-rumus saja, bukan pada pemahaman konsep [20]. Pembelajaran IPA tidak bisa hanya dengan cara menghafal atau pasif mendengarkan guru menjelaskan konsep namun siswa sendiri yang harus melakukan pembelajaran melalui percobaan, pengamatan maupun bereksperimen [21]. Hal tersebut dapat memudahkan siswa dalam memahami pelajaran IPA.

Sikap merupakan hal yang penting bagi peserta didik dalam proses pembelajaran [22]. Proses pembelajaran adalah suatu kegiatan yang dirancang untuk membantu peserta didik mempelajarai suatu kemampuan dan atau nilai yang baru [23]. Proses pembelajaran yang menarik akan membuat siswa tertarik dan aktif untuk belajar [24]. Salah satu aspek keberhasilan siswa dalam belajar adalah bagiamana sikap siswa saat pembelajaran berlangsung [25]. Sikap disiplin itu sendiri terbukti meningkatkan kualitas belajar. Hasil belajar peserta didik ditentukan oleh bagaimana partisiapsi mereka pada proses pembelajaran [26]. Peserta didik yang inovatif dan kompeten akan meningkatkan kualitas pendidikan [27] Sesuai dengan penelitian sebelumnya [28], siswa menjadi lebih baik dan juga siswa yang memiliki sikap disiplin pasti perilaku dan pola pikirnya berbeda, siswa tersebut cenderung mengerjakan tugas tepat waktu, masuk kelas tepat waktu, mentaati aturan yang ada disekolahnya serta tidak melanggar tata tertib sekolah. Siswa yang disiplin akan merasa senang saat belajar. Sikap disiplin siswa dapat dilihat ketika siswa mempersiapkan pembelajaran sebelum pembelajaran dimulai, baik diluar kelas maupun di dalam kelas [29]. Sejalan dengan pendapat [30], perilaku peserta didik yang disiplin ditunjukkan bagaimana kecenderungan dan kebiasaan peserta didik dalam mengikuti kegiatan belajar IPA, peserta didik yang disiplin akan menunjukkan respon yang bersungguh-sungguh, aktif dan beminat mengikuti pelajaran IPA. Hasil belajarnya juga akan berpengaruh, sebagian siswa ada yang tidak mentaati peraturan sekolah karena tidak adanya rasa kedisiplinannya yang dimiliki dari diri siswa tersebut. Tidak tertibnya siswa disekolah seharusnya membuat lebih ketat lagi peraturan yang ada disekolah agar siswa bisa lebih disiplin terhadap tata tertib yang telah dibuat. Disiplin pada dasarnya dimiliki oleh setiap siswa, tetapi sebagian kurang disiplin karena faktor lingkungan yang sangat mempengaruhi

\section{KESIMPULAN}

Berdasarkan dari hasil penelitian yang telah dilakukan sesuai dengan tujuan awal peneliti untuk mengidentifikasi sikap kedisiplinan peserta didik telah didapatkan hasil bahwa sikap kedisiplinan pada pelajaran IPA di SMPN 19 Kota Jambi berada pada kategori baik. Siswa yang displin khususnya pada mata pelajaran IPA akan berpengaruh pada hasil belajar peserta didik. Siswa yang disiplin akan mentaati peraturan sekolah, mengerjakan tugas tepat waktu, dan tidak melanggar tata tertib yang ada di sekolah. Dari perilakuperilaku tersebut akan membuat hasil belajar peserta didik tinggi. 


\section{UCAPAN TERIMA KASIH}

Peneliti mengucapkan terimakasih kepada kepala sekolah SMPN 19 Kota Jambi, guru IPA SMPN 19 Kota Jambi, serta siswa-siswi kelas VII E dan VII F yang telah berpartisipasi dalam penelitian ini. Semoga penelitian ini membawa dampak yang positif bagi guru, siswa, dan penelitian selanjutnya.

\section{REFERENSI}

[1] Suryani, R. S., \& Fitriani, R. S, "Deskripsi Sikap Kesenangan dalam Belajar IPA, Ketertarikan Memperbanyak Waktu Belajar IPA, dan Ketertarikan Berkarir di Bidang IPA di MTS Syifa'ul Qulub". Integrated Science Education Journal (ISEJ). vol. 1, no. 1. pp. 39-43, 2020.

[2] Senjawati, "Peran guru kelas dalam meningkatkan pemahaman siswa pada pembelajaran IPA melalui pembelajaran berbasis etnosains". Integrated Science Education Journal (ISEJ). vol. 1, no. 2. pp. 46-50, 2020.

[3] Haryanto, Asrial, \& Ernawati. M. D. W, "E-Worksheet for Science Processing Skills Using Kvisoft Flipbook". iJOE. vol 16, no 3. pp. 46-59, 2020

[4] Fujika, A., Anggraeni, E., \& Budiarti, R. S, "Analisis Kemampuan Berpikir Kritis Siswa Sma N 5 Kota Jambi Melalui Pembelajaran Berbasis Masalah Pada Konsep Pencemaran Lingkungan”. Jurnal Biodik. vol 1, no. 1. pp. 1$10,2015$.

[5] Asfadi, B., Yeliati, U., \& Budiarti, R. S, "Pengaruh Model Pembelajaran Berbasis Masalah (Problem Based Learning) Terhadap Hasil Belajar Biologi Siswa Kelas X SMA N 3 Kota Jambi”. Pendidikan Biologi. pp. 1-8, 2014 ,

[6] Dewi, R., Budiarti, R. S., \& Aina, M, "Pengembangan Lembar Kegiatan Peserta Didik (LKPD) Bermuatan Pendidikan Karakter Dengan Model Pembelajaran Guided Inquiry Pada Materi Bakteri Bagi Siswa Kelas X Sekolah Menengah Atas”. Jurnal Biodik. vol 3, no. 1. pp. 17-26, 2017.

[7] D. Renfiani, "Pengaruh Disiplin Belajar Siswa Kelas VIII B SMP Negeri 1 Statbat Terhadad Pembentukan Perilaku”. SEJ. vol. 7, no. 1. pp. 120-123, 2017

[8] E. Ariananda, dkk., "Pengaruh Kedisiplinan Siswa Di Sekolah Terhadap Prestasi Belajar Siswa Teknik Pendingin”. Journal Of Mechanical Engineering Education. vol. 1 no. 2. pp.233- 238, 2014.

[9] Garlans sina, "The inspiration learning”. Jakarta : garudhawaca, 2015.

[10] Chusnani,Diana, "Pendidikan Karakter Melalui Sains. Jurnal Kebijakan dan Pengembangan Pendidikan”. vol. 1, no. 1,2013

[11] Marasabesy, "Analisis Pengelolaan Pembelajaran Yang Dilakukan Oleh Guru Yang Sudah Tersertifikasi Dan Yang Belum Tersertifikasi Pada Pembelajaran IPA Di Kelas V Sekolah Dasar”. vol. 13, no. 1. pp. 6-13, 2012.

[12] D.A, Kurniawan, A. Astalini, D.Darmaji, R. Meisayanti, "Students Attitude Toward Natural Science". International Journal of Evaluation and Research in Education (IJERE) vol. 8, no. 3. pp. 455- 460, 2019.

[13] Suryani \& Hendrayadi. Metode Riset Kuantitatif : Teori Dan Aplikasi Pada Penelitian Bidang Manajemen Dan Ekonomi Islam. Jakarta : Prenada Media Group, 2015.

[14] D. Renfiani, "Pengaruh Disiplin Belajar Siswa Kelas VIII B SMP Negeri 1 Statbat Terhadad Pembentukan Perilaku". SEJ. vol. 7, no. 1. pp. 120-123, 2017.

[15] Taniredja,. T \& Mustafidah. H. Penelitian Kuantitatif. Bandung : Alfabeta, 2014.

[16] Yediarani, R. D., Maison, Syarkowi, A, "Scientific Reasoning Abilities Profil of Junior High School Students in Jambi”. Indonesian Journal of Science and Education. vol. 3, no. 2. pp. 21-25, 2019.

[17] Tanti, Isnadi, H., \& Maison, "Konstruksi Dan Validasi Bahan Ajar Fisika Berbasis Masalah (Problem-Based Learning) Untuk Meningkatkan Keterampilan Generic Siswa”. JoTaLP: Journal of Teaching and Learning Physics. vol 5, no. 1. pp. 28-34, 2020.

[18] Maison, Syahrial, Syamsurizal, \& Tanti, "Learning Environment, Students' Beliefs, And Self-Regulation In Learning Physics: Structural Equation Modeling”. Journal of Baltic Science Education. vol. 18, no. 3. pp. 389-403, 2019. https://doi.org/10.33225/jbse/19.18.389

[19] Putri, A. R., Maison, \& Darmaji, "Kerjasama Dan Kekompakan Siswa Dalam Pembelajaran Fisika Di Kelas XII MIPA SMAN 3 Kota Jambi”. EduFisika:Jurnal Pendidikan Fisika. vol 3, no. 2. pp. 32-40, 2018

[20] Tanti, Jamaluddin, Syefrinando, B, "Pengaruh Pembelajaran Berbasis Masalah Terhadap Beliefs Siswa Tentang Fisika Dan Pembelajaran Fisika”. Jurnal Ilmiah Pendidikan Fisika Al-BiRuNi. vol. 06, no. 1. pp. 23-36, 2017.

[21] G, Nugroho, “Analisis motivasi belajar siswa pada pembelajaran IPA di SDN 16/ii Sepunggur”. Integrated Science Education Journal (ISEJ). vol 1, no 2. pp.67-71, 2020.

[22] Astalini, Maison, Ikhlas. M., \& Kurniawan, D. A, "Pengembangan Instrumen Sikap Mahasiswa Terhadap Mata Kuliah Fisika Matematika”. EDUSAINS. vol. 10, no. 1. pp. 46-52, 2018. 
[23] Adburahman, Gradjito, \& Budiarti, R. S, "Pengembangan Lembar Kegiatan Siswa Berbasis Penemuan Terbimbing Pada Materi Struktur Dan Fungsi Jaringan Tumbuhan Kelas XI SMA”. vol. 1, no 1. pp. 1-8, 2015.

[24] Budiarti, R. S, \& Sadikin, A, "Pengaruh Kartu Kwartet Animalia Dengan Model Tgt Terhadap Pemahaman Materi Taksonomi Hewan Siswa Sman 8 Kota Jambi”. vol. 1, no. 1. pp. 1-9, 2015

[25] Paino \& Desmawan, W, "Analisis sikap siswa pada pembelajaran IPA di SDN 124/VIII Sidorejo Kabupaten Tebo". Integrated Science Education Journal (ISEJ). vol 1, no. 2. pp. 51-55, 2020.

[26] M, Muazza., Mukminin, A., Habibi, A., Sari, S. R., Haryanto, E., \& Hidayat, M, “Indonesian teachers' perception on classroom management: A sequential exploratory study on the process and problems". vol. 9, no. 4. pp. 1159$1182,2019$.

[27] Tanti, Rahim, \& Sampradja, H, "Pengaruh Model Problem Based Learning Terhadap Kemampuan Pemecahan Masalah Matematis Siswa Kelas VII SMP Negeri 14 Kendari”. Jurnal Penelitian Pendidikan Matematika. vol. 8 , no.2. pp.169-182, 2020.

[28] Supardi, "Peran Kedisiplinan Belajar Dan Kecerdasan Matematis Logis Dalam Pembelajaran Matematika". Jurnal Formatif. vol. 4, no. 2, 2014.

[29] Tanti, D. A. Kurniawan., R. Perdana., \& O. H. Wiza, “Comparison of Students' Attitudes toward Natural Sciences in Rural Middle Schools in Jambi Province”, Jurnal Ta'dib, vol. 23, no. 1, pp. 63-73. 2020.

[30] Kurniawan, N., \& Nurlaili, "Kedisiplinan siswa terhadap objek mata pelajaran IPA di SMP Kabupaten Muaro Jambi”. Integrated Science Education Journal (ISEJ). vol 1, no. 2. pp. 56-61, 2020. 